\title{
ANALYSIS OF FACTORS INCREASING THE PROBABILITY OF FUR CHEWING IN CHINCHILLA (CHINCHILLA LANIGERA) RAISED UNDER FARM CONDITIONS*
}

\author{
Stanisław Łapiński†, Marcin W. Lis, Anika Wójcik, Łukasz Migdał, Iwona Guja \\ Department of Poultry and Fur Animal Breeding and Animal Hygiene, University of Agriculture \\ in Krakow, al. Mickiewicza 24/28, 30-059 Kraków, Poland \\ •Corresponding author: s.lapinski@ur.krakow.pl
}

\begin{abstract}
The aim of the study was to assess the extent of fur chewing problems on chinchilla farms. The research was based on a 20-question survey addressed to breeders. A total of 47 anonymous questionnaires were answered. Results showed that the problem of fur chewing was found in as many as $85 \%$ of the farms but the proportion of affected animals was usually low (mean $\pm \mathrm{SE}: 3.5 \pm 0.55 \%$ ). To determine the relationship between herd size and the extent of the problem, the Pearson's correlation coefficient was calculated to be $r=-0.315(P \leq 0.05)$, possibly indicating the problem to be more severe on smaller farms. No correlation was found between fur chewing and the type of fodder (pellets from different producers), temperature, humidity, type of cage equipment or frequency of dust baths. Moreover, the level of fur-biting animals kept on a deep-litter floor was estimated at $1.7 \%$ while the level of those kept on a wire floor and in a mixed system was 2.8-times higher $(\mathrm{P} \leq \mathbf{0 . 0 5})$. The fact that $37.5 \%$ of the respondents perceived the predisposition to fur chewing to be hereditary was an important observation suggesting a direction for further research. A considerable proportion of those surveyed (37.5\%) also pointed to a greater excitability among fur chewers. To sum up, results of the present study revealed that keeping animals on litter reduces the incidence of fur chewing. Breeders' observations also suggest that fur biting may be determined genetically and/or connected with impulsive-compulsive disorders; however, more detailed studies are necessary to confirm these hypotheses.
\end{abstract}

Key words: chinchilla, fur chewing, stereotypical behaviour, impulsive-compulsive disorder

Chinchillas are fur-bearing animals that have been raised under farm conditions since the 1920s. As with any animal species, problems arise during the course of their breeding for production purposes. In chinchillas, the most common and difficult problem to overcome is fur chewing (fur biting). Its etiology has not been conclusively established but various causative factors have been considered. They can be divided into two major groups: environmental factors (housing conditions, nutrition, underlying disease, mental stress) (Ponzio et al., 2007, 2012) and genetic factors (Sulik, 2009). Among the underlying disease factors, special note is taken of

\footnotetext{
*Work financed from DS 3210/KHDZFIZ University of Agriculture in Krakow, Poland.
} 
Cushing's syndrome, which leads to secondary enlargement of the adrenal cortex and increases the secretion of cortisol. One of the possible pathologies that could be mistaken for self-inflicted barbering is seasonal alopecia. Administration of melatonin may prove helpful in the therapy for this disease (Tisljar et al., 2002). Sulik (2009) also considers psychological factors, mainly stress experienced by animals on farms. The most recurrent stress-inducing stimuli include disturbing animals by routine procedures, introduction of novel objects to the farm, persistent and sudden noise, or boredom associated with the monotony of life in cages resulting partly from lack of cage enrichment (including objects for chewing) and lack of company. Exposure to long-term stress can lead to the development of repetitive behaviours induced by frustration, repeated attempts to cope and/or central nervous system dysfunction known as impulsive-compulsive disorder (Mason and Rushen, 2006). These animals deviate from normal behaviour patterns that are typically found in a given age and sex and in more natural environments (Kowalski, 2005).

The aim of this study was to assess the extent of fur chewing problems on chinchilla farms, to analyse the farm conditions, and to identify the most probable causes of fur chewing.

\section{Material and methods}

In the first stage of this research, a detailed questionnaire was prepared. After piloting the survey and making necessary corrections, it was addressed to Polish breeders taking part in chinchilla seminars and exhibitions in Kraków and Myślenice (Poland). From a total number of 50 anonymous questionnaires, 47 were answered. There were 20 questions in the survey:

1. Have you had cases of fur chewing on your farm, now or in the past?

2. If fur chewing occurred in the past but not now, what changes were introduced?

3. Approximately how many animals were affected by fur chewing?

4. In which group of animals were cases of fur chewing most prevalent?

5. How many animals are on your farm?

6 . What is the average temperature on your farm?

7. What is the average humidity on your farm?

8. Are the animals exposed to sudden noises?

9. Which housing system do you use?

10. Which type of bath do you use?

11. Which type of bath dust do you use?

12. How often do your animals take a bath?

13. Which pellets do you feed your chinchillas?

14. Do your animals receive supplements other than pellets?

15. Have you observed an increase in fur chewing in any season of the year?

16. Have you observed fur chewing to increase in connection with the animal's age?

17. Does the storey of the cage affect fur chewing? 
18. Is mycosis a problem on your farm?

19. Have you observed the tendency towards fur chewing to be hereditary?

20. Do you think that fur chewers differ in temperament from non-chewers?

The completed questionnaires were grouped according to the answers, thus providing information about the incidence of fur chewing on the farms, the number of animals in a herd, herd structure, animal housing systems, the solutions used by the breeders and also their own observations about fur chewing in chinchillas.

The dependence between occurrence of fur-chewing problems (FCP) and factors such as actions taken to reduce FCP, the housing system, groups of animals intended for breeding and those for fur production, exposure to noise, use of drawer or rotary bath basin and type of bath dust, frequency of bath and numeric data such as scale of FCP, size of herd, temperature, and humidity were analysed by means of a two-way ANOVA. Differences between the groups were determined using Tukey's test. The differences between percent values were calculated by using z tests, and relationships between herd size and number of FCP were calculated by means of Pearson's correlation coefficient. The results obtained were analysed statistically at a $\mathrm{P} \leq 0.05$ level of significance. Statistica 9.1 software (StatSoft, Inc. 2010) was used to perform analysis.

\section{Results}

The respondent farms were mostly located in southern (60\%) and central $(26 \%)$ Poland and their sizes ranged from 24 to 650 females (median 120) in farms that used wire, wood shavings litter and mixed housing systems (Table 1). Most of the analysed farms were small and stocked up to 200 mothers (83\%), which is typical for chinchilla breeding facilities in Poland. Only two farms kept more than 500 breeding females.

Table 1. Characteristics of farms, depending on housing system

\begin{tabular}{l|c|c|c}
\hline \multicolumn{1}{c|}{ Housing system } & $\begin{array}{c}\text { Number of farms } \\
(\mathrm{n}=47)\end{array}$ & $\begin{array}{c}\text { Number of animals } \\
(\mathrm{n}=6873)\end{array}$ & $\begin{array}{c}\text { Average size of the herd } \\
(\mathrm{mean} \pm \mathrm{SD})\end{array}$ \\
\hline Wire & $36 \%$ & $54 \%$ & $219 \pm 179.3$ \\
Litter & $38 \%$ & $24 \%$ & $93 \pm 57.3$ \\
Mixed & $26 \%$ & $22 \%$ & $124 \pm 48.8$ \\
\hline
\end{tabular}

Results of this study indicate that FCP were found in most farms $(85 \%, \mathrm{P} \leq 0.05)$. However, FCP usually concerned a few animals in the herd (mean \pm SE: $3.5 \pm 0.55 \%$, range $0-15 \%$ ) although they were observed in both breeding and fur-production animals and in all age groups ( $\mathrm{P}>0.05$; Table 2$)$. Fur biting was more severe on mediumsized farms $(65 \%)$ than on small $(10 \%)$ and large ones $(10 \%)(\mathrm{P} \leq 0.05$, Table 2$)$. Simultaneously, the frequency of FCP and the size of the herd showed a weak correlation amounting to $\mathrm{r}=-0.315(\mathrm{P} \leq 0.05)$. Most respondent breeders $(55 \%)$ tried to prevent FCP by changing the feeding (35.5\%) and less often by culling $(12.5 \%)$ or transferring animals to other cages $(7.5 \%)(\mathrm{P} \leq 0.05$; Table 2$)$. 


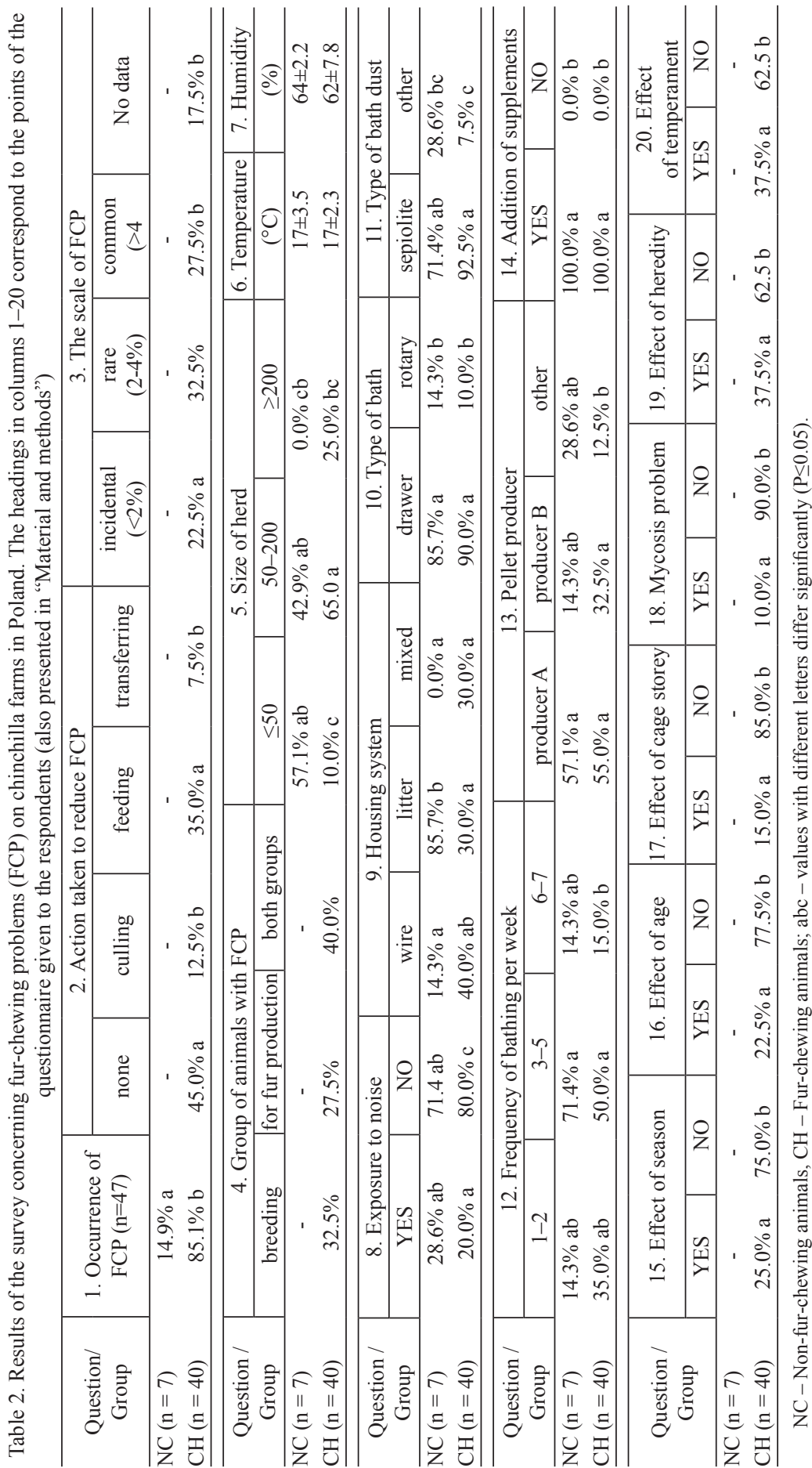


Our survey found no relationship between fur chewing and season, temperature $\left(17^{\circ} \mathrm{C}\right.$, range $\left.10-20^{\circ} \mathrm{C}\right)$, relative humidity $(62 \%$, range $40-75 \%)$, type of bath basin, type of bath dust or frequency of dust bathing per week (Table 2). Moreover, most breeders used fodders from the same producers and also used dietary supplements (such as hay and herbs), blocks for teeth grinding, and twigs for chewing as well as salt, vitamins and probiotics (Table 2).

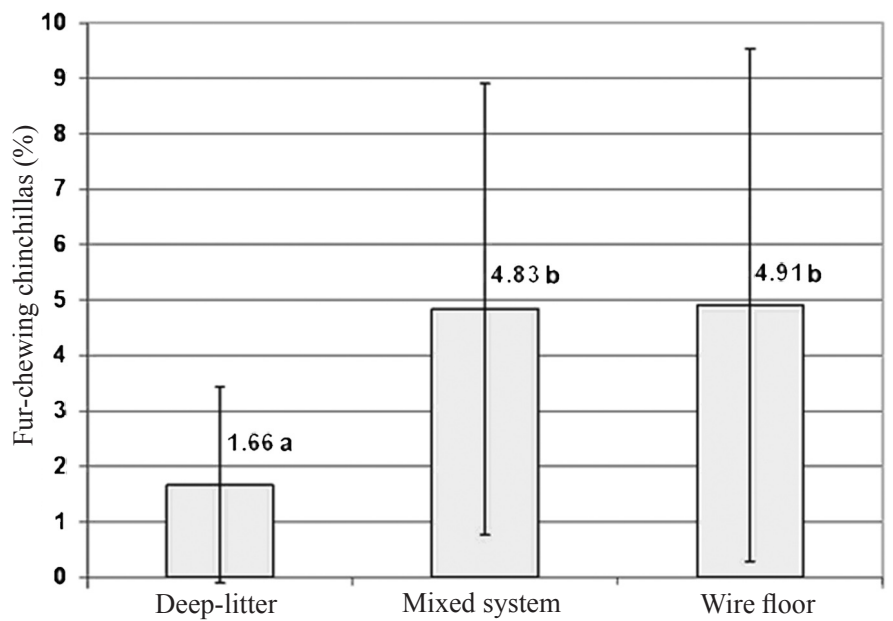

$\mathrm{a}, \mathrm{b}$ - different letters indicate significant differences $(\mathrm{P} \leq 0.05)$.

Fig. 1. Percentage of fur-chewing chinchillas on farms with different housing systems

The results of the present survey revealed that the housing system can significantly affect fur chewing $(\mathrm{P} \leq 0.05)$. The percent of fur-biting animals kept on deep litter was estimated at $1.7 \pm 0.49 \%$ while on the wire floor and in the mixed system it was 2.8-times higher $(\mathrm{P} \leq 0.05$, Figure 1$)$. Simultaneously, the cage storey and dermal mycosis problem seemed to have no effect on FCP ( $\mathrm{P} \leq 0.05$; Table 2$)$. Nevertheless, $37.5 \%$ of breeders indicated that fur chewing occurred in animals of greater excitability (greater fearfulness or aggression). Moreover, most of the respondents perceived that the predisposition to fur chewing was hereditary.

\section{Discussion}

Our survey showed that lack of knowledge regarding the etiology of fur chewing by chinchillas resulted in farmers not taking action to prevent this phenomenon. Assuming that the problem stemmed from environmental factors, a considerable proportion of the breeders made changes to the cage equipment or feeding, or moved animals to other cages. Nutritional deficiencies were regarded as one of the most fre- 
quent causes of fur chewing. One hypothesis suggests that fur chewing is promoted by crude fibre deficiency (Fehr, 2009). Improper nutrition of the chinchillas, which results from vitamin B complex deficiency and fatty degeneration of the liver, can impair hair growth and make hair more brittle (Egri et al., 1994). However, in the opinions of the surveyed breeders, when the chinchillas received optimized complete pellets and other fodder supplements, cases of fur biting can usually be eliminated. This is consistent with the opinion that fur chewing is not caused by nutritional deficiencies, because of the absence of fur in the gastrointestinal tract of affected animals (Tisljar et al., 2002).

The housing system appears to be an important factor having a significant effect on fur chewing in animals. On the basis of the presented survey which concerns rearing conditions, it can be stated that all of the surveyed breeders keep animals under conditions recommended for chinchilla farms (Tombarkiewicz et al., 2003, 2006). Nevertheless, our survey indicated that FCP was more severe on farms with fewer than 200 animals. However, this finding may result from breeders on large farms who may pay less attention to the true extent of the problem.

On the other hand, stress-induced fur chewing that resulted from the loneliness of individually housed animals was observed in degus (Octodon degus) (Ewringmann and Glöckner, 2005). Ponzio et al. (2007, 2012) and Sulik (2009) found that factors such as noise, mismatched company or lack of company, the appearance of foreign people on the farm, and boredom predisposed animals to engage in fur-chewing behaviour. Kozłow (2009) also reported that sawdust beddings kept chinchillas entertained and reduced predisposition to fur chewing. Therefore, it cannot be excluded that the relation between greater excitability (greater fearfulness or aggression) and fur chewing (indicated by $37.5 \%$ of respondents), which is an impulsive-compulsive disorder, can result from frustration (stress) caused by environmental factors (Greer and Capecchi, 2002). However, the majority of respondents perceived that the predisposition to fur chewing was hereditary, as considered by Sulik (2009). The genetic predisposition to fur chewing has also been found in other species of animals. In a study that concerned mice, a mutation in the Hoxb8 gene was considered as an underlying genetic factor behind fur chewing (Greer and Capecchi, 2002). This gene is a member of the mammalian Hox complex and contains 39 transcription factors. Hox genes are involved in embryonic development, hair formation in adult mice and mutations in mammary tissue of female mice. When kept separately, mice with mutations in the Hoxb8 gene pulled or chewed their fur excessively. In this way, they left large skin areas without fur, especially on the lateral and ventral parts of the body, which resembled trichotillomania. All mutants showed normal reactions to pain, heat and cold. Most of their behaviours were the same as in normal mice except for fur chewing, hair pulling and self-mutilation (Kurien et al., 2005).

In conclusion, the results obtained in the present survey highlight areas for future research into chinchilla fur-chewing problems. There is evidence that the incidence of fur biting was significantly lower when animals were kept on litter compared to wire floors. Therefore, it is highly possible that the predisposition to fur chewing is affected by stress factors and/or is genetically determined. 


\section{References}

Egri B.J., Egri J., Haj n ovi c s B. (1994). Fatty liver in young male chinchilla (Chinchilla velligera). Tierarztl. Umschau, 49: 45-47.

Ewringmann A., G1öckner B. (2005). Leitsymptome bei Meerschweinchen, Chinchilla und Degu: Diagnostischer Leitfaden und Therapie. Enke, Stuttgart.

F e h r M. (2009). Chinchilla (in Polish). In: Gabrisch K., Zwart P. (eds.): Krankheiten der Heimtiere, 7th ed. Schlütersche Verlagsanstalt Hannover: 2008, Polish edition. Galaktyka, Łódź, pp. 171-198.

Gre e r J., C a p e c ch i M. (2002). Hoxb8 is required for normal grooming behavior in mice. Neuron, 33: $23-34$

Kowalski A. (2005). Stereotypies as an indicator of animal welfare (in Polish). Med. Weter., 61: $1335-1339$.

K o złow A. (2009). Fur biting - disease or bad habit? Self chewing of chinchillas and animal welfare (in Polish). KZHS Myślenice, Zesz. Hod., 8: 10-14.

K uri e n B., Gros s T., S c of i e ld R. (2005). Barbering in mice: a model for trichotillomania. BMJ, 331: 1503-1505.

M a s on G., Ru she n J. (2006). Editors. Stereotypic animal behaviour: Fundamentals and applications to welfare. 2nd ed. CAB International, Wallingford OXON.

Ponzio M.F., Busso J.M., Ruiz R.D., Fiol de Cuneo M. (2007). A survey assessment of the incidence of fur-chewing in commercial chinchilla (Chinchilla lanigera) farms. Anim. Welfare, 16: 471-479.

Ponzio M.F., Monfort S.L., Busso J.M., Carlini V.P., Ruiz R.D., Fiol de Cuneo M. (2012). Adrenal activity and anxiety-like behaviour in fur-chewing chinchillas (Chinchilla lanigera). Horm. Behav., 61: 758-762.

S u li k M. (2009). Problems of fur chewing of chinchillas. Self chewing of chinchillas and animal welfare (in Polish). KZHS Myślenice, Zesz. Hod., 8: 15-19.

Tis ljar M., Janić D., Grabarević Z., Simpraga B., Marinculić A., Pinter L., Jani ck i Z., Neman ic A. (2002). Stress-induced Cushing's syndrome in fur-chewing chinchillas. Acta Vet. Hung., 50: 133-142.

To mbarkiewicz B., S ze leszczuk O., Niedziółk a J., R a pa c z A. (2003). Hygienic conditions in cages and reproductive performance of the chinchilla (Chinchilla velligera). Pr. Kom. Nauk. Rol. Biol. BTN, B, 51: 275-280.

To m barkiewicz B., P a w lak K., Niedziółk a J. (2006). Temperature and humidity distribution in multi-storey cages in chinchilla-houses. Book of Abstracts. Proc. XXXVI Annual Meeting, ESNA, Iasi, Romania, 10-14.09.2006, p. 44. 